\title{
A Defesa Nacional no Plano Plurianual 2016-2019: uma avaliação a partir dos PROJETOS ESTRATÉGICOS ${ }^{1}$
}

\author{
Luís Felipe Giesteira² \\ Patrícia de Oliveira Matos ${ }^{3}$ \\ Thiago Borne Ferreira ${ }^{4}$
}

\section{INTRODUÇÃO}

A defesa nacional é uma atividade estatal cercada de polêmica, complexidade e hermetismo. Apesar de constituir função basilar do Estado, mesmo pesquisadores experientes encontram dificuldades em tratá-la de forma objetiva e rigorosa. Como política pública, é refratária aos métodos de avaliação tradicionais. Náo é trivial avaliar o impacto ou definir a clientela da política de defesa e não é raro que a ampliaçáo do escopo das atividades militares para áreas com públicos mais facilmente delimitáveis seja vista como inadequada ou gere desconfiança, sobretudo em países com histórico de ativa presença militar interna como é o caso do Brasil.

Partindo-se de uma abordagem formal-conceitual, por exemplo, dir-se-ia que a defesa serve ao conjunto da sociedade, e que seu foco é essencialmente evitar conflitos externos. Não ocorrendo eventos desse tipo, o objetivo da defesa estaria 100\% atendido. Restaria no máximo indagar se o mesmo resultado teria sido conseguido com menos recursos.

Evidentemente, essa é uma perspectiva limitada. Inicialmente, há que se considerar o texto constitucional. Há também a questâo frequentemente evocada de que a capacidade militar de cada país tem de estar relativamente alinhada com seu peso internacional, de modo a náo se constituir em restrição para a atividade diplomática e oferecer efeitos dissuasórios compatíveis com esse peso. Mais além, a efetividade verificada no passado pode ser erodida por alteraçôes no cenário internacional ou por mudança tecnológica contundente, de forma que muitas das atividades realizadas hoje estão de fato definindo a capacidade dissuasória futura.

Nesse contexto, o exame do Plano Plurianual (PPA) surge como importante suporte. Sua principal vantagem é oferecer parâmetros numéricos objetivos e, em tese, legitimados política e socialmente. Trata-se, ademais, de parâmetros comparáveis com outras instâncias de políticas públicas. Apesar de parte significativa do que é feito no âmbito militar ser de difícil avaliaçáo por terceiros, ou estar coberto por alguma forma de sigilo, o fato de as Forças Armadas contarem com um robusto conjunto de documentos de planejamento a longo prazo - a Política de Defesa Nacional (PDN), a Estratégia Nacional de Defesa (END), o Livro Branco de Defesa Nacional (LBDN) e o Plano de Articulaçáo e Equipamentos de Defesa (PAED) - oferece parâmetros que permitem compreender de modo mais abrangente o PPA de defesa.

1. DOI: http://dx.doi.org/10.38116/bapi28art8

2. Especialista em políticas públicas e gestão governamental; e coordenador de estudos em governança e instituições internacionais na Diretoria de Estudos e Relações Econômicas e Políticas Internacionais (Dinte) do Ipea.

3. Professora do Programa de Pós-graduação em Ciências Aeroespaciais da Universidade da Força Aérea (Unifa).

4. Professor de relações internacionais da Universidade do Vale do Taquari (Univates). 
O esforço de pesquisa gerou a necessidade de referenciar programas do PPA “afins" ou "de interesse" da defesa - o espacial e o nuclear - por sua evidente mas frequentemente não formalizada vinculação com os projetos estratégicos. Ao tomar esses projetos como régua, este artigo sustenta uma visão recorrente, mas nem por isso livre de polêmicas, de que o desenvolvimento científico e tecnológico autônomo é o desafio estratégico central das FA.

A seção a seguir explora as conexóes entre o PPA e os chamados documentos articuladores da defesa no contexto orçamentário compreendido entre os anos de 2015 e 2019. Na sequência, são descritas as relaçóes do programa de defesa com outros programas afins e analisado o desempenho de cada um deles. A última seção conclui o trabalho, chamando atenção para as principais descobertas desta investigação.

\section{OS DOCUMENTOS ARTICULADORES DA DEFESA E O CONTEXTO ORÇAMENTÁRIO DO PPA 2016-2019}

A PDN é o instrumento de orientação de longo prazo para as atividades das Forças Armadas por excelência. Sua primeira edição, à qual se seguiram outras quatro, é de 1996. A PDN oferece orientaçóes na forma de diretrizes e objetivos, tais como: "contribuir para o incremento da projeção do Brasil no concerto das naçôes e sua inserção em processos decisórios internacionais" e "ampliar o envolvimento da sociedade brasileira nos assuntos de Defesa Nacional”. ${ }^{5}$ É um rol enxuto, contendo pouco mais de dez itens, que não sofreu alteraçóes significativas nos últimos anos.

A END por seu turno, é considerada o documento orientador mais importante das atividades das Forças Armadas, explicitando os objetivos da PDN. Entre outras disposiçóes, o texto define os três setores estratégicos prioritários das Forças Armadas - o cibernético, o espacial e o nuclear -, colocando cada um deles sob responsabilidade do Exército, da Força Aérea Brasileira (FAB) e da Marinha, respectivamente.

Considerando que o marco legal referente às funções constitucionais das Forças Armadas e ao processo orçamentário datam do final dos anos 1980, vale indagar por que apenas em 2008 foi formalizada uma primeira estratégia. Três condicionantes parecem relevantes: o amadurecimento do debate sobre a "grande estratégia brasileira" dos anos 1990 (Nunes e Svartman, 2019), a percepção de que o Brasil estaria ingressando em um novo ciclo econômico expansivo e a ideia de que a ordem global caminhava para a multipolaridade. Evidências em prol dessa percepção estão presentes na própria END, que postula conexão das atividades de defesa com a política internacional e com o desenvolvimento nacional como um todo, em particular, o tecnológico. ${ }^{6}$

Seguiram-se à END, o LBDN e o PAED, ambos publicados em 2012. O foco do primeiro documento é a divulgação internacional da END; e do segundo, publicado como anexo daquele, seu desdobramento orçamentário. Todos esses textos foram, após discussão no Executivo, acolhidos em dispositivos legais aprovados pelo Congresso Nacional, fornecendo relevante referência para avaliar os PPAs que se seguiram.

5. Disponível em: <https://www.gov.br/capes/pt-br/centrais-de-conteudo/politica-nacional-de-defesa-pdf>.

6. Corroboram a ideia de que a END era um plano de desenvolvimento mais amplo que deveria dialogar com outras políticas públicas, a Política de Desenvolvimento Produtivo (PDP), o Plano Brasil Maior (PBM) e a Estratégia Nacional de Ciência, Tecnologia e Inovação (ENCTI), todos elaborados na virada da década passada para a atual. Ademais, o Banco Nacional de Desenvolvimento (BNDES) e a Financiadora de Estudos e Projetos (Finep) criaram estruturas próprias para apoiar alguns projetos militares mais robustos. A Finep lançou, em 2013, um programa específico mobilizando diversos atores da base industrial de defesa (BID) e de organizações militares chamado Inova Aero Defesa, com dotação de $R \$ 2,9$ bilhões. 
O PAED, em particular, oferece um conjunto relativamente extenso de programas/projetos estratégicos, bem como projeções orçamentárias que totalizam aproximadamente R \$ 396,6 bilhóes de investimentos previstos entre 2013 e 2033 . Anualizado, tal valor correspondia a aproximadamente $0,4 \%$ do produto interno bruto (PIB) em 2012 e, somado ao gasto com defesa próximo de 1,5\% do PIB na média dos anos anteriores, seria coerente com a reiterada meta de atingir $2 \%$ do PIB em gastos com defesa.

As dificuldades econômicas enfrentadas pelo Brasil desde 2012 indicam porque a meta de $2 \%$ do PIB jamais se materializou. É relevante observar, contudo, que tal patamar não parecia irrealista até virada do século, quando os primeiros documentos articuladores de defesa começaram a ser preparados.

GRÁFICO 1

Brasil: dispêndios com defesa como proporção do PIB (1993-2019)

(Em \%)

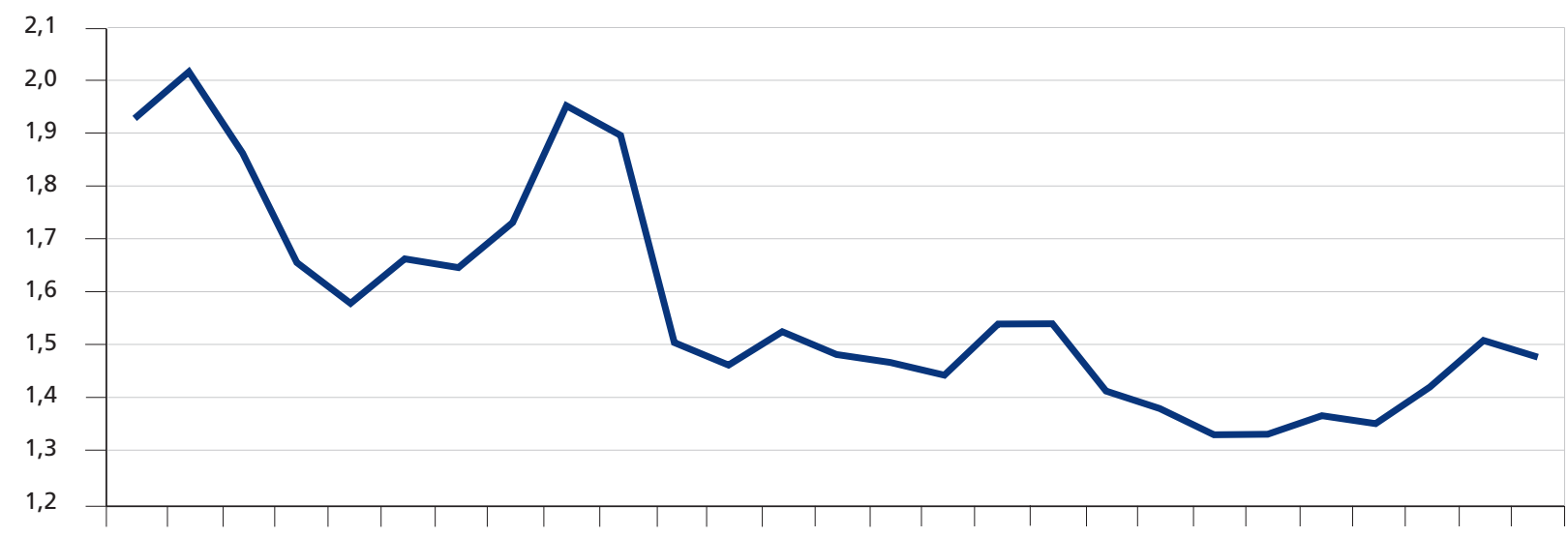

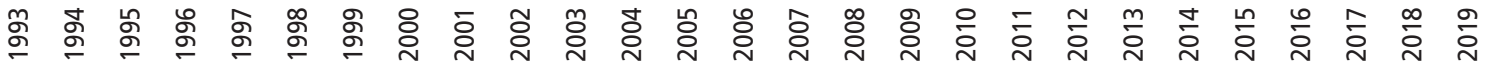

Fonte: Instituto Internacional de Pesquisa da Paz de Estocolmo (Stockholm International Peace Research Institute - SIPRI), 2020.

Apesar de os recursos alocados para a defesa após a elaboração do PAED terem se situado muito aquém do projetado, ${ }^{7}$ durante o PPA 2016-2019 ocorreu uma recuperação parcial do nível verificado anteriormente. De 1,37\% do PIB em 2015, chegou-se a 1,47\% em 2019, depois de um "pico" de 1,51\% em 2018. Trata-se de uma evolução significativa, que explica em parte a notável redução da parcela do orçamento dedicada a pagamento de pessoal. ${ }^{8}$ 


\section{GRÁFICO 2}

Brasil: participação dos gastos com pessoal e encargos (pago) no orçamento do Ministério da Defesa (MD) (2015-2019) (Em \%)

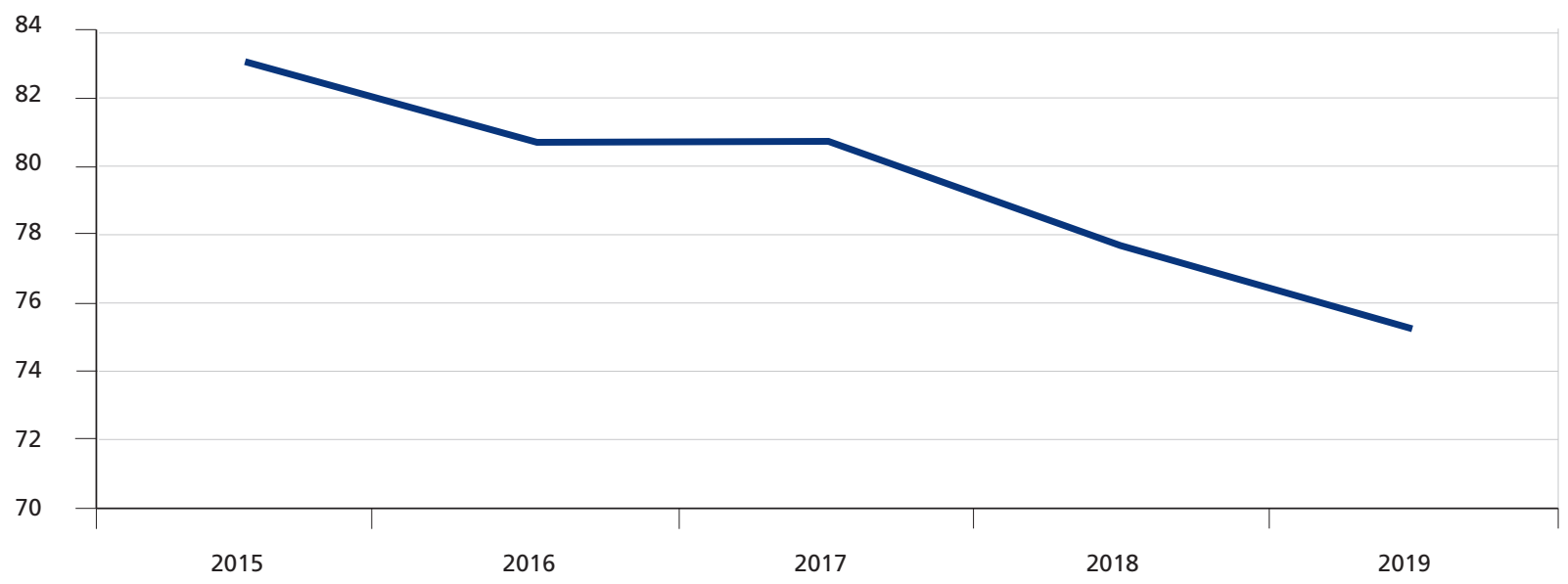

Elaboração dos autores.

Do crescimento nominal total do orçamento ( $\mathrm{R} \$ 27,2$ bilhóes), $\mathrm{R} \$ 9,9$ bilhóes - ou seja, 36,5\% do total - foram destinados a despesas de capital. Dessa forma, a soma de investimentos e inversóes financeiras do MD passaram de 3,7\% do orçamento em 2015 para 12,6\% pagos em 2019. Boa parte disso se deve ao salto em inversóes e encargos financeiros - correspondente fundamentalmente à capitalização das empresas estatais envolvidas no desenvolvimento dos projetos/programas estratégicos, em particular, a Amazônia Azul Tecnologias de Defesa (Amazul) e a Empresa Gerencial de Projetos Navais (Emgepron). Esses dispêndios passaram de R \$ 298 milhóes para R \$ 7,15 bilhóes nesse período. Ainda assim, os investimentos stricto sensu passaram de $\mathrm{R}$ \$ 2,47 bilhóes (3,34\% do total) para $\mathrm{R}$ \$ 5,54 bilhóes (5,49\% do total) no período.

Com efeito, em 2019, o MD, com 22\% do total, passou a ser a pasta com maiores investimentos federais, com montantes superiores aos de transportes, infraestrutura e desenvolvimento regional.

GRÁFICO 3

Brasil: participação dos investimentos do MD e de outros ministérios no investimento federal (2015-2019) (Em \%)

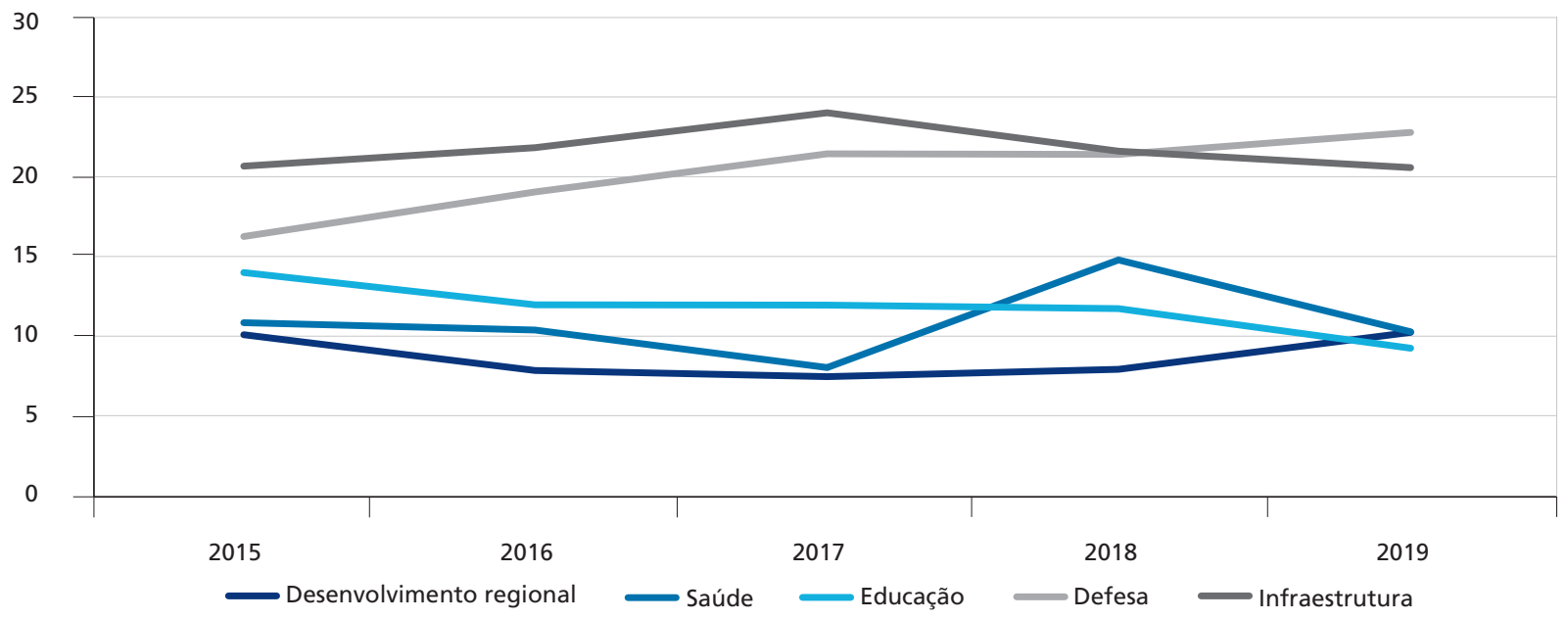


Qual teria sido o impacto dessa melhora - em tese - do perfil do gasto em defesa? Tentamos responder a essa questáo a partir de dois questionamentos. O PPA da Defesa de fato corresponde aos objetivos elencados nos documentos articuladores elaborados entre 2008 e 2012? Os resultados atingidos apontam para um nível adequado de efetividade dos recursos disponibilizados?

\section{DESEMPENHO DOS PROGRAMAS RELACIONADOS À DEFESA NACIONAL NO PPA}

A função defesa esteve presente no orçamento de 2019 a partir de nove programas. Destes, apenas quatro - Defesa Nacional; Oceanos, Zona Costeira e Antártica; Gestão e Manutenção do MD; e Outros Encargos Especiais - tiverem recursos alocados no ano em questão. Os demais receberam apenas "restos a pagar".

Além do programa Oceanos, Zona Costeira e Antártica, há outros dois que não tem vinculação formal ao $\mathrm{MD}$, mas que possuem importância central para a consecução da END e do PAED: a Política Espacial e a Política Nuclear, ambos a cargo do Ministério da Ciência, Tecnologia e Inovação (MCTI).

O programa Oceanos, Zona Costeira e Antártica congrega iniciativas sob responsabilidade dos ministérios do Meio Ambiente e de Minas e Energia, do já mencionado MCTI e do próprio MD. Cabem a este último, no âmbito desse programa, as seguintes metas: i) obter a ampliação da Plataforma Continental; ii) manter a taxa de atendimento logístico de demanda de pesquisa em 60\%; iii) reconstruir a Estação Antártica Comandante Ferraz; iv) concluir a primeira versão do Plano de Uso Compartilhado do Ambiente Marinho a partir do Planejamento Espacial Marinho; e v) instalar uma estação científica em Fernando de Noronha. Sem embargo, embora possa-se atribuir caráter estratégico a esse conjunto - que gera, ademais, sinergias potencialmente relevantes, como no caso da prospecção mineral no Elevado do Rio Grande (a cargo do Ministério das Minas e Energia) -, nenhuma dessas metas pode ser conectada ao PAED.

No caso da Política Nuclear, todos os indicadores possuem relação com o avanço no Programa Nuclear da Marinha (PNM), que integra o PAED, mas não o PPA, sendo dois de forma direta: a produção de bens e serviços nucleares; e o índice de nacionalização do ciclo nuclear. Ademais, são metas relevantes pela perspectiva dos documentos articuladores da defesa: i) produzir oito equipamentos e componentes para as indústrias nuclear e de alta tecnologia, sendo um para usina nuclear Angra 3, três para o submarino nuclear e quatro cascos de submarinos convencionais; e ii) atingir 20\% do empreendimento Reator Multipropósito Brasileiro - ambas, diferentemente das metas do programa Oceanos, Zona Costeira e Antártica, não estão sob responsabilidade do MD. ${ }^{9}$

O mesmo ocorre com o programa Política Espacial, que inclui as seguintes metas imbricadas com objetivos estratégicos da defesa: i) concluir o desenvolvimento de Sistema de Controle de Atitude e Órbita e de Supervisão de Bordo de satélites; ii) concluir o modelo de engenharia do motor foguete a propelente líquido de 7,5 toneladas de empuxo; iii) firmar seis contratos de prestação de serviços de engenharia para a transferência de tecnologias espaciais no âmbito do Programa de Transferência de Tecnologia do Satélite Geoestacionário de Defesa e Comunicações Estratégicas (SGDC); e iv) realizar voo de qualificação do Veículo Lançador de Microssatélites (VLM-1) com carga útil nacional.

9. Restringimo-nos aqui a considerar metas no PPA. É relevante, contudo, observar que existem ações orçamentárias a cargo do MD que contribuem indiretamente, ao menos via spin offs, para o atingimento das metas explicitadas no PPA. Por exemplo, a tecnologia nuclear da Marinha. 
Novamente, trata-se de metas importantes para os projetos estratégicos do MD, embora a responsabilidade formal caiba ao MCTI. Entretanto, no caso da Política Espacial, vale mencionar que existem as açóes relevantes para as quais contribuem organizaçóes militares, em particular, o Departamento de Ciência e Tecnologia Aeroespacial (DCTA)/FAB. No caso da Política Nuclear, a participação da Marinha, embora importante, é mediada.

Observadas essas relevantes peculiaridades, a tabela 1 apresenta a trajetória dos indicadores do programa Defesa Nacional, expressos em percentagem, durante o período de vigência do PPA 2016-2019.

TABELA 1

Brasil: programa Defesa Nacional (2016-2019)

(Em \%)

\begin{tabular}{lccccc}
\hline Indicador & Referência & 2016 & 2017 & 2018 & 2019 \\
\hline Disponibilidade da frota FAB & 40,1 & 41,1 & 40,2 & 40,9 & 40,6 \\
Índice de operacionalidade da Força Terrestre & 45,0 & 50,0 & 78,3 & 81,5 & 74,4 \\
Meios operativos da Marinha, na condição de pronto para operar & 48,0 & 44,0 & 47,0 & 46,0 & 47,0 \\
Monitoramento do espaço aéreo & 93,1 & 93,1 & 93,1 & 93,1 & 93,1 \\
Participação da BID no PIB & 0,1500 & 0,1254 & 0,1270 & 0,1610 & 0,1657 \\
\hline
\end{tabular}

Fonte: Brasil (2015).

Observa-se que essas variáveis guardam correspondência com o PAED e outros documentos nos quais a preocupação com a efetividade operacional se combina com o apoio ao desenvolvimento da BID.

No que diz respeito a sua evolução, apenas a referente à operacionalidade da Marinha mostrou-se desfavorável, ao passo que sua equivalente para o Exército exibiu evolução muito positiva. Cabe destaque à participação da BID no PIB. A política de defesa possui incidência apenas indireta, mediada e defasada sobre essa variável. Assim, o valor verificado em 2016 não teria como refletir ações realizadas no PPA 2016-2019, sendo mais correto considerar a variação de 0,13\% para 0,17\%, registrando incremento de $30 \%$.

Sobre as metas do programa Defesa Nacional, boa parte foi parcial ou plenamente atingida, perfazendo em média $80,6 \%$. Esse patamar compara-se favoravelmente ao padrão geral de todas as metas da versão final do PPA, que chegou a 66,3\%.

Não obstante, esse desempenho foi desigual. Como costuma acontecer com outras políticas públicas, metas sob controle mais estrito, de âmbito administrativo, avançaram mais, enquanto metas mais desafiadoras e em geral mais importantes do ponto de vista estratégico avançaram menos. Uma observação da exaustiva lista evidencia isso na tabela 2.

Destaques negativos cabem ao Projeto LINK-BR2 e ao Polo de Ciência e Tecnologia de Guaratiba. Algumas metas, entratanto, apesar de não atingidas, apresentaram, no contexto orçamentário restrito, desempenho apreciável, como a modernização de aeronaves e o Sistema Astros. Mais relevante, provavelmente, é o fato de alguns projetos amiúde referidos como estratégicos, como o rádio por software e o Míssil Antinavio de Superfície (MASUP) não constarem desse rol. 


\section{TABELA 2}

Brasil: evolução das metas do programa Defesa Nacional durante o PPA 2016-20191

\begin{tabular}{|c|c|c|c|c|}
\hline Metas & 2016 & 2017 & 2018 & 2019 \\
\hline Aumentar de $50 \%$ para $60 \%$ a adequação das organizações militares na Amazônia & 56 & 60 & 62 & 64 \\
\hline Aumentar de $75 \%$ para $80 \%$ a adequação das organizações militares fora da Amazônia & 79 & 80 & 82 & 84 \\
\hline Concluir a construção de um hangar para a aeronave KC-390 & 0 & 0 & 0 & 0 \\
\hline Modernizar ou revitalizar $15 \%$ das organizações militares terrestres da Marinha & 3,92 & 7,52 & 11,51 & 15,93 \\
\hline Adquirir 22 aeronaves militares & 2 & 3 & 4 & 8 \\
\hline Atingir $35,8 \%$ do desenvolvimento do Projeto F-X2 (aeronave caça multimissão) & 4,11 & 8,6 & 17,56 & 22,74 \\
\hline Implantar 85\% do Sistema de Lançadores Múltiplos de Foguetes Astros 2020 & 40 & 44 & 49 & 52 \\
\hline Incorporar dez meios navais, aeronavais e de fuzileiros navais & 2 & 4 & 9 & 11 \\
\hline Modernizar quinze meios navais, aeronavais e de fuzileiros navais & 4 & 5 & 8 & 11 \\
\hline Modernizar dezessete aeronaves militares & 10 & 12 & 13 & 16 \\
\hline Obter trezentas viaturas da nova família de blindados sobre rodas & 35 & 96 & 137 & 197 \\
\hline $\begin{array}{l}\text { Apoiar a participação de } 3.725 \text { universitários no Projeto Rondon, para o fortalecimento da } \\
\text { consciência cidadã }\end{array}$ & 750 & $1.402,00$ & $2.217,00$ & $2.973,00$ \\
\hline $\begin{array}{l}\text { Atender a } 75 \% \text { dos municípios na área de abrangência do Programa Calha Norte com projetos } \\
\text { de implantação e melhoria da infraestrutura básica nas áreas de segurança e defesa, economia, } \\
\text { educação, saúde, social, transportes e esportes }\end{array}$ & 42 & 76,28 & 75 & 80 \\
\hline $\begin{array}{l}\text { Capacitar profissionalmente } 31.398 \text { jovens egressos do serviço militar para inserção no mercado de } \\
\text { trabalho - Projeto Soldado-Cidadão }\end{array}$ & $8.066,00$ & $13.813,00$ & $26.280,00$ & $35.342,00$ \\
\hline Formar e capacitar 23.900 profissionais aquaviários & $10.889,00$ & $22.043,00$ & $33.851,00$ & $45.909,00$ \\
\hline Alcançar 50\% do Projeto de Modernização do Sistema de Comando e Controle do Exército & 40 & 43 & 46 & 50 \\
\hline Implantar 5,6\% do Programa da Defesa Cibernética na Defesa Nacional & 1 & 2 & 3 & 5,6 \\
\hline Alterar a composição do quantitativo de graduados temporários da FAB de $10 \%$ para $19,7 \%$ & 7 & 6,8 & 10 & 8,7 \\
\hline Alterar a composição do quantitativo de oficiais temporários da FAB de $40 \%$ para $41 \%$ & 30,71 & 39,9 & 40,1 & 40,5 \\
\hline Capacitar 8 mil servidores civis em áreas de interesse da Defesa, em instituiç̧ões de qualidade reconhecida & $5.378,00$ & $7.765,00$ & $9.472,00$ & $11.519,00$ \\
\hline Formar e capacitar 54 mil militares da Marinha & $17.024,00$ & $40.319,00$ & $68.558,00$ & $114.041,00$ \\
\hline Formar e capacitar 60 mil militares do Exército Brasileiro & $16.015,00$ & $34.028,00$ & $49.336,00$ & $70.592,00$ \\
\hline Alcançar índice de $65 \%$ dos meios operativos da Marinha na condição pronto para operar & 44 & 47 & 46 & 47 \\
\hline Aprimorar e promover o treinamento anual de $63 \%$ do efetivo das unidades operacionais do Exército & 90 & 80 & 91,21 & 63 \\
\hline $\begin{array}{l}\text { Reduzir o período médio entre treinamentos em simulador de voo das tripulações operacionais de } \\
30 \text { meses para } 24 \text { meses }\end{array}$ & 36 & 24 & 24 & 24 \\
\hline $\begin{array}{l}\text { Concluir a implantação do Sistema Integrado de Monitoramento de Fronteiras (Sisfron) no estado } \\
\text { do Mato Grosso do Sul }\end{array}$ & 0,45 & 0,5 & 0,56 & 0,61 \\
\hline $\begin{array}{l}\text { Elevar a cobertura de vigilância aérea no território nacional de } 47 \% \text { para } 75 \% \text {, com ampliação do } \\
\text { monitoramento na altitude de } 3.300 \mathrm{~m}\end{array}$ & 53,48 & 68,2 & 68,2 & 68,2 \\
\hline $\begin{array}{l}\text { Implantar } 26 \text { módulos de defesa antiaérea de estruturas civis críticas - Projeto de Defesa Antiaérea } \\
\text { da Força Terrestre }\end{array}$ & 5 & 23 & 23 & 23 \\
\hline Implantar 9\% do Sisfron nos estados do Acre, Mato Grosso, Rondônia, Paraná e Santa Catarina & 0,3 & 1,16 & 2,04 & 2,8 \\
\hline Realizar, anualmente, cem operações de fiscalização das águas jurisdicionais brasileiras & 124 & 120 & 79 & 80 \\
\hline Realizar dezenove exercícios militares conjuntos & 4 & 8 & 16 & 20 \\
\hline Ampliar em 4\% ao ano o volume de exportações da BID & $-11,2$ & $-25,68$ & 30,94 & 25,91 \\
\hline $\begin{array}{l}\text { Catalogar 38\% dos produtos de defesa, de acordo com o padrão internacional do Sistema Otan de } \\
\text { Catalogação (SOC)/Organização do Tratado do Atlântico Norte (Otan) }\end{array}$ & 20 & 80 & 80 & 80 \\
\hline Concluir o desenvolvimento do míssil A-DARTER (em \%) & 95 & 96 & 99 & 100 \\
\hline Concluir o programa de ensaios e a certificação da aeronave KC-390 (em \%) & 0 & 97 & 97 & 95 \\
\hline Concluir o Projeto de Enlace de Dados Ar-Ar e Terra-Ar (Projeto LINK-BR2) (em \%) & 0 & 0 & 0 & 26 \\
\hline Implantar 25,4\% do Polo de Ciência e Tecnologia do Exército em Guaratiba/Rio de Janeiro (PCTEG) & 2,7 & 3,31 & 3,31 & 3,31 \\
\hline
\end{tabular}

Fonte: Brasil (2015).

Nota: ${ }^{1}$ Dados das metas em unidades e em \%, conforme o enunciado de cada meta. 
Os indicadores dos outros três programas supracitados descreveram a trajetória durante o período de vigência do PPA 2016-2019 (tabela 3).

TABELA 3

Brasil: programas de interesse da Defesa desvinculados do MD ${ }^{1}$

\begin{tabular}{|c|c|c|c|c|c|c|}
\hline Programa & Indicador & Referência & 2016 & 2017 & 2018 & 2019 \\
\hline $\begin{array}{l}\text { Oceanos, Zona } \\
\text { Costeira e Antártica }\end{array}$ & $\begin{array}{l}\text { Cumprimento do Plano de Trabalho de Exploração de } \\
\text { Crostas Cobaltíferas na Elevação do Rio Grande (\%) }\end{array}$ & 0 & 10 & 23,3 & 23,3 & 76 \\
\hline $\begin{array}{l}\text { Oceanos, Zona } \\
\text { Costeira e Antártica }\end{array}$ & $\begin{array}{l}\text { Levantamento do potencial mineral e biológico, bem como } \\
\text { das variáveis oceanográficas da Plataforma Continental } \\
\text { Jurídica Brasileira e dos fundos marinhos internacionais } \\
\text { (número de levantamentos) }\end{array}$ & 0 & 0 & 50400000 & 50400000 & 113740000 \\
\hline $\begin{array}{l}\text { Oceanos, Zona } \\
\text { Costeira e Antártica }\end{array}$ & $\begin{array}{l}\text { Taxa de atendimento logístico da demanda de pesquisa } \\
\text { em oceanos e na Antártica (\%) }\end{array}$ & 87 & 84,81 & 86,48 & 94,99 & 98,95 \\
\hline Política Espacial & $\begin{array}{l}\text { Grau de Autonomia Nacional em Imagens de Satélites de } \\
\text { Observação da Terra (GAOT) (\%) }\end{array}$ & 25 & 21,67 & 46,47 & 46,7 & 81,19 \\
\hline Política Espacial & $\begin{array}{l}\text { Índice de Participação do Setor Empresarial Nacional no } \\
\text { Programa Temático Política Espacial (IPSEN-2) (\%) }\end{array}$ & 30,56 & 20,7 & 32,91 & 32,91 & 35,53 \\
\hline Política Nuclear & $\begin{array}{l}\text { Exames de medicina nuclear utilizando radiofármaco (em } \\
\text { número de exames) }\end{array}$ & 1328745 & 1600000 & 1464000 & 1155 & 1753349 \\
\hline Política Nuclear & $\begin{array}{l}\text { Produtos e serviços tecnológicos desenvolvidos na área } \\
\text { nuclear e em áreas correlatas }\end{array}$ & 24 & 18 & 20 & 16 & 22 \\
\hline Política Nuclear & Taxa de nacionalização do ciclo do combustível nuclear (\%) & 67,4 & 69,9 & 69,9 & 72,5 & 75,1 \\
\hline
\end{tabular}

Fonte: Brasil (2015).

Nota: ${ }^{1}$ Para unidade de medida de cada indicador, observar parênteses na segunda coluna.

Apenas dois deles possuem pouca relação com a defesa (a exploração do elevado de Rio Grande e o uso de radiofármacos na realizaçáo de exames médicos). Os demais, ainda que dependam fundamentalmente da atuação de órgáos externos ao $\mathrm{MD}$, são relevantes para avançar no que se postula nos documentos de defesa.

De forma geral, a evolução dos indicadores foi, novamente, favorável. Cabe destaque ao indicador taxa de atendimento logístico da demanda de pesquisa, que atingiu quase 100\% de execuçáo em 2019. É notável que isso tenha ocorrido a despeito da deterioração do indicador de nível de operacionalidade da Marinha. Também é notável que a meta do programa Oceanos, Zona Costeira e Antártica referente à presença de pesquisadores no arquipélago de São Pedro e São Paulo, tenha sido subtraída no decurso do PPA, aparecendo em sua versão inicial, mas não na final. No mesmo sentido, o levantamento do potencial mineral e biológico da plataforma continental, provavelmente em sinergia com o indicador anterior, apresentou significativo progresso. Também avançou o grau de autonomia nacional em imagens de satélites, provavelmente beneficiado pelo lançamento do SGDC e do satélite Sino-Brasileiro CBERS-4 no período.

O único indicador que se deteriorou foi o de bens e serviços tecnológicos intensivos em tecnologia nuclear ofertados, contrastando com o avanço na nacionalização do ciclo de combustível nuclear, que alcançou 75,1\% em 2019. Os demais indicadores apresentaram evolução favorável.

O indicador do programa espacial posição no índice de competitividade espacial (Space Competitiveness Index-SCI), no qual o Brasil figurava na $11^{\mathfrak{a} \text { a }}$ posição em 2015, não constava na versão final do PPA. Ainda no que diz respeito ao programa espacial, mas inserido no programa Oceanos, Zona Costeira e Antártica, o indicador área abrangida por instrumento de Planejamento Espacial Marinho também foi excluído da versão final. 
No que diz respeito à realização das metas dos três programas auxiliares, a taxa ficou aquém da atingida pelo Defesa Nacional, totalizando $57,2 \%{ }^{10}$

TABELA 4

Brasil: metas de programas do PPA relacionados à Defesa e evolução das variáveis respectivas

\begin{tabular}{|c|c|c|c|c|c|}
\hline Programas & Metas & 2016 & 2017 & 2018 & 2019 \\
\hline \multirow{6}{*}{$\begin{array}{l}\text { Oceanos, Zona } \\
\text { Costeira e Antártica }\end{array}$} & Obter a ampliação do limite da Plataforma Continental Brasileira para até 350 milhas & 200 & 200 & 0 & 200 \\
\hline & Manter a taxa de atendimento logístico de demanda de pesquisa em 60\% & 69,63 & 69,63 & 84,97 & 84,97 \\
\hline & $\begin{array}{l}\text { Reconstruir a Estação Antártica Comandante Ferraz conforme padrões de sustentabilidade } \\
\text { ambiental aplicáveis à Antártica }\end{array}$ & 47 & 69 & 81 & 90 \\
\hline & Instalar uma estação científica no arquipélago de Fernando de Noronha & 5 & 8 & 9 & 12 \\
\hline & Atualizar o macrodiagnóstico de $100 \%$ da Zona Costeira, na escala da União & 25 & 25 & 50 & 50 \\
\hline & $\begin{array}{l}\text { Concluir a primeira versão do Plano de Uso Compartilhado do Ambiente Marinho a partir do } \\
\text { Planejamento Espacial Marinho }\end{array}$ & 0 & 0,2 & 0,42 & 0,15 \\
\hline \multirow{4}{*}{ Política Espacial } & $\begin{array}{l}\text { Concluir o desenvolvimento de Sistema de Controle de Atitude e Órbita e de Supervisão de } \\
\text { Bordo de satélites }\end{array}$ & 0 & 0 & 0 & 0,1 \\
\hline & $\begin{array}{l}\text { Concluir o modelo de engenharia do motor foguete a propelente líquido de } 7,5 \text { toneladas de } \\
\text { empuxo, em continuidade ao desenvolvimento do motor }\end{array}$ & 0 & 0,33 & 0,37 & 0,4 \\
\hline & $\begin{array}{l}\text { Firmar seis contratos de prestação de serviços de engenharia para a transferência de } \\
\text { tecnologias espaciais a indústrias nacionais ou entidades governamentais no âmbito do } \\
\text { Programa de Transferência de Tecnologia do SGDC }\end{array}$ & 5 & 5 & 5 & 6 \\
\hline & Realizar voo de qualificação do VLM-1 com carga útil nacional & 0 & 0,3 & 0,36 & 0,5 \\
\hline \multirow[b]{2}{*}{ Política Nuclear } & Atingir 20\% do empreendimento reator multipropósito brasileiro & 14 & 17,1 & 20,4 & 22,3 \\
\hline & $\begin{array}{l}\text { Produzir oito equipamentos e componentes para as indústrias nuclear e de alta tecnologia, } \\
\text { sendo um para usina nuclear Angra-III, três para o submarino nuclear e quatro cascos de } \\
\text { submarinos convencionais }\end{array}$ & 2 & 2 & 2 & 5 \\
\hline
\end{tabular}

Fonte: Brasil (2015).

As duas metas com pior desempenho - instalação de base científica em Fernando de Noronha e plano de uso compartilhado do ambiente marinho - dependem de recursos fiscais e da contribuição de órgãos externos ao MD.

As metas mais relacionadas ao aumento da autonomia tecnológica - na verdade todas as provenientes da Política Nuclear e da Política Espacial - alcançaram 60,4\% de realização. Esse resultado foi beneficiado por duas metas com 100\% de performance, das quais uma é relevante para o PNM o avanço no reator multipropósito brasileiro, cuja base de conhecimento é compartilhada com a construção do reator do submarino nuclear (SN-BR).

A outra meta com 100\% de realização - referente aos contratos de transferência de tecnologia no âmbito do SGDC - é importante, mas não representa em si um passo relevante na autonomia tecnológica nacional. Mesmo que se inclua esse número, as metas referentes ao programa Política Espacial atingiriam apenas 50\%. Trata-se, pelo que o PPA permite observar, do resultado que mais requer atenção do ponto de vista do progresso nas atividades estratégicas da defesa nacional. ${ }^{11}$ O cenário extremamente adverso em que se movem as atividades espaciais de 2012 em diante, com queda real de mais de $70 \%$, ajuda a compreender esse resultado.

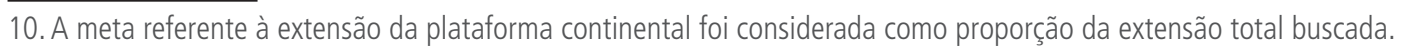

11. É relevante observar que, no que diz respeito ao sistema de controle de órbita e atitude de satélites, essa é uma tecnologia que teria passado a ser dominada pelo Brasil, mais especificamente pela Visiona, empresa controlada pela Empresa Brasileira de Aeronáutica (Embraer), e pela Telecomunicações Brasileiras (Telebrás), na vigência do PPA em tela. Disponível em: <https://cutt.ly/FzxZ74i>. 


\section{GRÁFICO 4}

Brasil: orçamento do Programa Espacial (2010-2019)

(Em R\$ milhões de 2019)

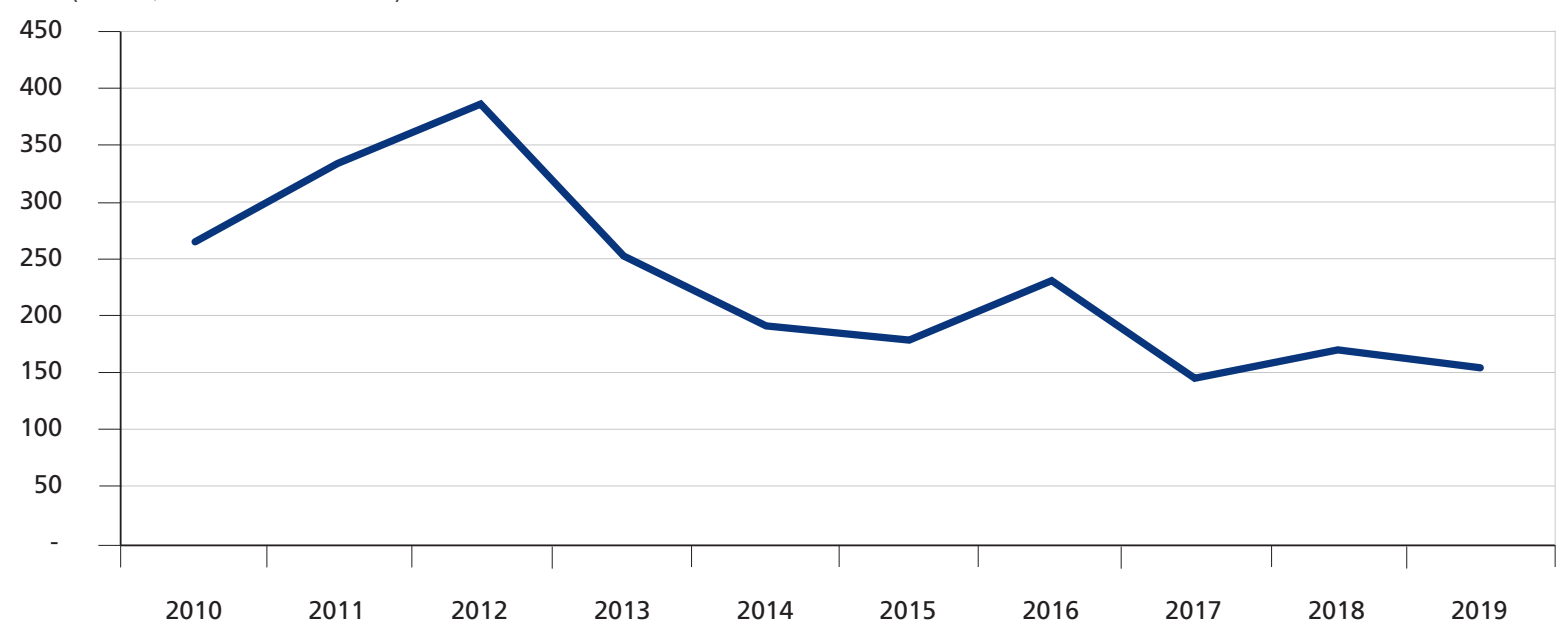

Elaboração dos autores.

Outra causa plausível para a lenta evolução do Programa Espacial é sua estrutura de governança, composta de diferentes órgãos, unidades orçamentárias e programas. Na realidade, a gestão das metas relacionadas à PND, e aos setores estratégicos, que estão presentes em programas diferentes, alguns dos quais não subordinados diretamente ao $\mathrm{MD}$, pode ser dificultada por essa complexidade estrutural/administrativa.

Não obstante, embora esse problema pareça se repetir na política nuclear - ainda com o agravante de a Marinha não dispor, como a FAB, de uma Instituição Científica, Tecnológica e de Inovação (ICT) sob seu comando -, os números do PPA sugerem a prevalência do aspecto orçamentário como decisivo. Apesar de modesto e com evolução menos favorável do que o da defesa, o orçamento do Programa Nuclear comparou-se vantajosamente com o Espacial no período recente.

\section{GRÁFICO 5}

Brasil: orçamento do Programa Nuclear (2010-2019)

(Em R\$ milhões de 2019)

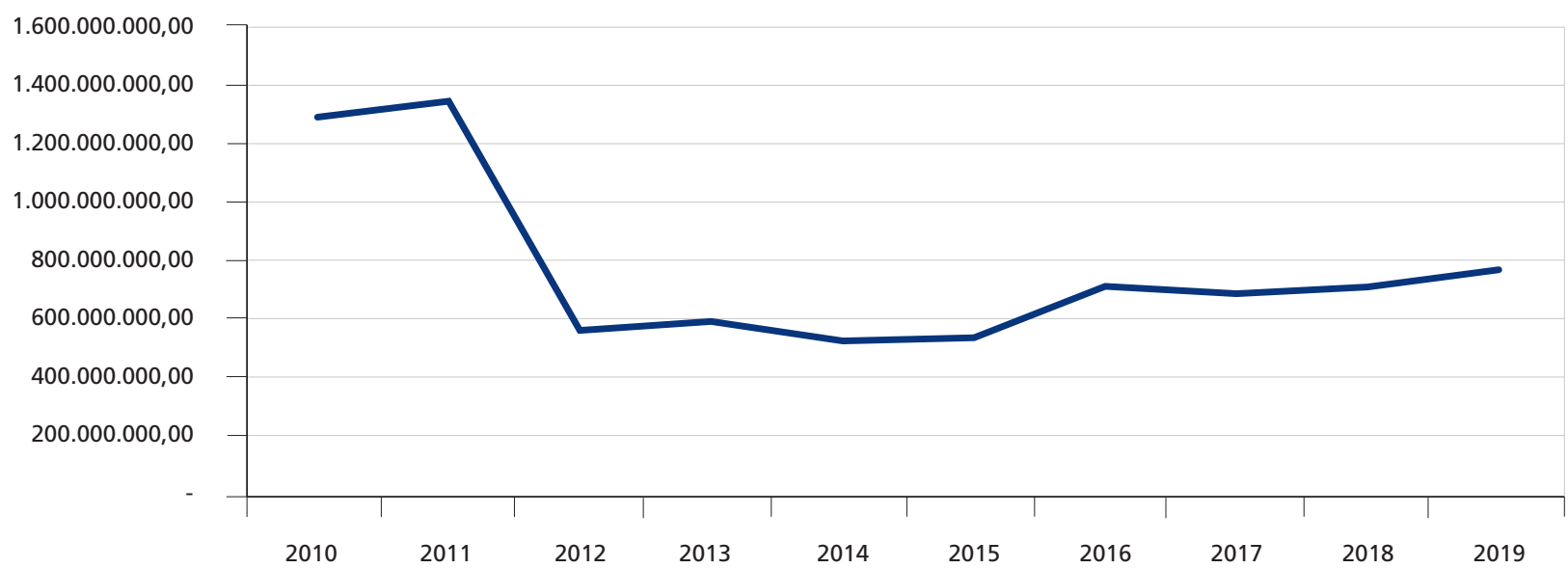

Elaboração dos autores. 
Embora, em média, o Programa Nuclear tenha até superado o Defesa Nacional, com 81,3\% de atingimento, além de sua limitada abrangência (são apenas duas metas), é visível sua modéstia. Um debate em maior profundidade sobre a defesa brasileira, tendo por perspectiva o que estabelecem os documentos articuladores da defesa, haveria de incluí-lo como tema merecedor de redobrada atenção.

\section{CONSIDERAÇÕES FINAIS}

Há significativa correspondência entre os projetos estratégicos de defesa e indicadores, metas, ações e objetivos do programa Defesa Nacional no PPA 2016-2019. Essa vinculação é facilitada pela redação abrangente de alguns desses projetos. Ademais, há projetos “sem metas" no PPA, bem como desproporção entre a importância de alguns projetos estratégicos e as metas com que melhor se relacionam. Dada a significativa frustração e instabilidade orçamentária do período considerado, bem como a incerteza tecnológica típica de alguns desses projetos, esses desvios são compreensíveis, mas não irrelevantes.

É importante notar o fato de que nas ações vinculadas ao programa Defesa Nacional os grandes setores estratégicos definidos na END, com exceção do cibernético. Há reiteradas declaraçóes dos comandantes das Forças Armadas e, sobretudo no caso do programa nuclear, ações orçamentárias significativas confirmando a relevância desses setores. No entanto, é preciso que se olhe para outros programas do PPA, externos ao MD, para vislumbrar como de fato os projetos estratégicos ganham força. Há ainda um programa - Oceanos, Zona Costeira e Antártica - cuja relação é menos direta com os projetos estratégicos como enunciados no PAED, mas que se coaduna com o propósito de ocupação e monitoramento das águas territoriais brasileiras e com o conceito de entorno estratégico, igualmente explicitados na END.

Menos notável que a correspondência formal entre documentos articuladores da defesa e PPA, essa desconexão sugere lapsos na governança desses setores estratégicos e dos programas que lhes correspondem. Em particular, chama atenção o fato de os programas Nuclear e Espacial não possuírem meta sob responsabilidade do MD.

A situação orçamentária peculiarmente grave dos dois programas reforça sinais de alerta. Em relação ao Programa Nuclear, o bom desempenho tanto dos indicadores quanto das metas respectivas o relativiza, mas o mesmo não ocorre no Programa Espacial. Nesse caso, a conjunção de governança confusa, perda de recursos orçamentários e baixo desempenho não permite suprimir a hipótese de o setor passar a representar, haja vista a sinergia que o une aos demais, um limitador decisivo para a autonomia tecnológica e para a própria capacidade dissuasória do país.

O programa Defesa Nacional, em contraste, apresentou desempenho em média bastante favorável, com mais de $80 \%$ de atingimento médio das metas, significantemente acima do desempenho do conjunto de todos os programas do PPA, com 66\% - embora algumas das metas potencialmente mais relevantes para a autonomia tecnológica terem obtido desempenho frustrante.

Esses reparos não impedem, no caso do programa Defesa Nacional, um balanço geral positivo, sobretudo ao se ter em conta que parte expressiva da expansão do orçamento no último PPA foi, como mencionado, destinada a gastos de capital, dos quais $25 \%$ no último ano foram destinados aos projetos estratégicos. Ainda observando elementos orçamentários não circunscritos ao PPA, os dados de despesas por função, de acordo com a classificação Despesas por Função do Governo Central (Classification of the Functions of Government - COFOG), indicaram o considerável montante de 
$\mathrm{R}$ \$ 1,6 bilhôes em pesquisa e desenvolvimento em 2019, o que representou 8,4\% do total federal nesse ano e sugere uma trajetória consistente de ênfase crescente na autonomia tecnológica.

Em conjunto, essas variáveis apontam para a necessidade de se adotar, sem perder de vista a objetividade e a comparabilidade, uma perspectiva contextual e articulada dos projetos estratégicos. Esse último elemento realça que eventualmente a forma como o gasto com pessoal é empregue pode ser mais pertinente do que uma alta taxa de investimento em capital físico, a qual pode resultar apenas de um surto de aquisiçóes de equipamentos a preços de ocasião no exterior.

Sob essa perspectiva, uma avaliação abrangente e mais conclusiva teria de considerar ao menos a articulação dessas açóes com as cadeias produtivas que abastecem os projetos estratégicos. Há indícios, por exemplo, de que é significativa a articulação entre a infraestrutura de ciência e tecnologia militar e empresas (Squeff, 2016). Resta saber se os esforços atuais estão sendo suficientes para contra-arrestar a desindustrialização e a perda de densidade tecnológica do tecido produtivo brasileiro nos últimos anos. Evidentemente, investigações adicionais são necessárias - tanto mais em um contexto em que, pressionada por grave conjuntura fiscal, a sociedade brasileira, legitimamente, busca elucidar melhor quão bem estão sendo empregados os recursos do setor público.

\section{REFERÊNCIAS}

ALMEIDA, P. R. de. Planejamento no Brasil: memória histórica. Parcerias Estratégicas, v. 9, n. 18, p. 157-190, 2004.

BORNE, T. Os programas estratégicos de defesa dez anos depois: dimensão tecnológica e dissuasória. Brasília: Ipea; Cepal, 2020. (Relatório Técnico). No prelo.

BRASIL. Plano Plurianual 2016-2019 - desenvolvimento, produtividade e inclusão social. Brasília: MP, 2015.

CARVALHO, J. M. de. Forças Armadas e política no Brasil. São Paulo: Todavia, 2005.

MARQUES, A. A. Concepçóes de Defesa Nacional no Brasil: 1950-1996. 2001. 153 f. Dissertação (Mestrado) - Universidade Estadual de Campinas, Campinas, 2001.

MATHIAS, S. K.; GUZZI, A. C.; GIANNINI, R. A. Aspectos da integração regional em Defesa no Cone Sul. Revista Brasileira de Política Internacional, v. 51, n. 1, p. 70-87, 2008.

MATOS, P. de O. Análise comparativa da evoluçáo dos orçamentos de Defesa e Segurança no período de 2007-2018. Brasília: Ipea; Cepal, 2020. (Relatório Técnico). No prelo.

MATOS, P. de O.; FINGOLO, J. M.; SCHNEIDER, R. A. Orçamento público e Defesa Nacional: uma análise do orçamento de Defesa brasileiro no período de 2000 a 2016 . Revista da Escola de Guerra Naval, v. 23, n. 1, p. 211-238, 2017. Disponível em: <https://revista.egn.mar.mil.br/index. php/revistadaegn/article/view/551>. Acesso em: 21 set. 2020.

NUNES, R. C.; SVARTMAN, E. M. Dilemas da grande estratégia das Forças Armadas do Brasil nos anos 1980 e 1990: o debate interno em um sistema internacional em transição. Revista Debates, v. 3, n. 2, 2019. Disponível em: <https://seer.ufrgs.br/debates/article/view/89392>. Acesso em: 21 set. 2020. 
SILVA, P. F. da. Base Industrial de Segurança e Defesa nacionais no Brasil: a janela de oportunidade da segurança integrada. In: ANDRADE, I. de O. et al. (Org.). Desafios contemporâneos para o Exército Brasileiro. Brasília: Ipea; Ceex, 2019.

SQUEFF, F. de H. S. Sistema Setorial de Inovação em Defesa: análise do caso do Brasil. In: DE NEGRI, F.; SQUEFF, F. de H. S. (Orgs.). Sistemas setoriais de inovaçáo e infraestrutura de pesquisa no Brasil. Brasília: Ipea; Finep; CNPq, 2016.

TONI, J. de. O planejamento estratégico governamental: reflexôes metodológicas e implicações na gestão pública. São Paulo: Intersaberes, 2016. 